NBER WORKING PAPER SERIES

\title{
RULE-OF-THUMB CONSUMERS AND THE DESIGN OF INTEREST RATE RULES
}

\author{
Jordi Galí \\ J. David López-Salido \\ Javier Vallés \\ Working Paper 10392 \\ http://www.nber.org/papers/w10392
NATIONAL BUREAU OF ECONOMIC RESEARCH 1050 Massachusetts Avenue
Cambridge, MA 02138
March 2004

We have benefited from comments by Bill Dupor, Ken West (the editor), an anonymous referee, and participants at the JMCB-Chicago Fed Tobin's Conference and the NBER Summer Institute, as well as seminars at the Federal Reserve Board, BIS, CREI-UPF, George Washington University and Bank of Spain. All remaining errors are our own. Galí acknowledges financial support from DURSI (Generalitat de Catalunya), MCYT (Grant SEC2002-03816) and the Bank of Spain. The views expressed in this paper do not necessarily represent those of the Bank of Spain. The views expressed herein are those of the author and not necessarily those of the National Bureau of Economic Research.

(C2004 by Jordi Galí, J. David López-Salido, and Javier Vallés. All rights reserved. Short sections of text, not to exceed two paragraphs, may be quoted without explicit permission provided that full credit, including (C) notice, is given to the source. 
Rule-of-Thumb Consumers and the Design of Interest Rate Rules

Jordi Galí, J. David López-Salido, and Javier Vallés

NBER Working Paper No. 10392

March 2004

JEL No. E32, E52

\title{
ABSTRACT
}

We introduce rule-of-thumb consumers in an otherwise standard dynamic sticky price model, and show how their presence can change dramatically the properties of widely used interest rate rules. In particular, the existence of a unique equilibrium is no longer guaranteed by an interest rate rule that satisfies the so called Taylor principle. Our findings call for caution when using estimates of interest rate rules in order to assess the merits of monetary policy in specific historical periods.

\author{
Jordi Galí \\ Ramon Trias Fargas 25 \\ 08005 Barcelona \\ SPAIN \\ and NBER \\ jordi.gali@upf.edu \\ J. David López-Salido \\ Bank of Spain \\ davidl@bde.es \\ Javier Vallés \\ Bank of Spain \\ valles@bde.es
}

Centre de Recerca en Economia Internacional (CREI) 


\section{Introduction}

The study of the properties of alternative monetary policy rules, and the assessment of their relative merits, has been one of the central themes of the recent literature on monetary policy. Many useful insights have emerged from that research, with implications for the practical conduct of monetary policy, and for our understanding of its role in different macroeconomic episodes.

Among some of the recurrent themes, much attention has been drawn to the potential benefits and dangers associated with simple interest rate rules. Thus, while it has been argued that simple interest rate rules can approximate well the performance of complex optimal rules in a variety of environments, ${ }^{1}$ those rules have also been shown to contain the seeds of unnecessary instability when improperly designed. ${ }^{2}$

A sufficiently strong feedback from endogenous target variables to the short-term nominal interest rate is often argued to be one of the requirements for the existence a locally unique rational expectations equilibrium and, hence, for the avoidance of indeterminacy and fluctuations driven by self-fulfilling expectations. For a large number of models used in applications that determinacy condition can be stated in a way that is both precise and general: the policy rule must imply an eventual increase in the real interest rate in response to a sustained increase in the rate of inflation. In other words, the monetary authority must adjust (possibly gradually) the short-term nominal rate more than one-for-one with changes in inflation. That condition, which following Woodford (2001) is often referred to as the Taylor principle, has also been taken as a benchmark for the purposes of evaluating the stabilizing role of central banks' policies in specific historical periods. Thus, some authors have hypothesized that the large and persistent fluctuations in inflation and output in the late $60 \mathrm{~s}$ and

\footnotetext{
${ }^{1}$ This is possibly the main conclusion from the contributions to the Taylor (1999a) volume.

${ }^{2}$ See, e.g., Kerr and King (1996), Bernanke and Woodford (1997), Taylor (1999b), Clarida, Galí and Gertler (2000), and Benhabib, Schmitt-Grohé, and Uribe (2001a,b), among others.
} 
70s in the U.S. may have been a consequence of the Federal Reserve's failure to meet the Taylor principle in that period; by contrast, the era of low and steady inflation that has characterized most of Volcker and Greenspan's tenure seems to have been associated with interest rate policies that satisfied the Taylor principle. ${ }^{3}$

In the present paper we show how the presence of non-Ricardian consumers may alter dramatically the properties of simple interest rate rules, and overturn some of the conventional results found in the literature. In particular, we analyze a standard new Keynesian model modified to allow for a fraction of consumers who do not borrow or save in order to smooth consumption, but instead follow a simple rule-of-thumb: each period they consume their current labor income.

To anticipate our main result: when the central bank follows a rule that implies an adjustment of the nominal interest rate in response to variations in current inflation and output, the size of the inflation coefficient that is required in order to rule out multiple equilibria is an increasing function of the weight of rule-of thumb consumers in the economy (for any given output coefficient). In particular, we show that if the weight of such rule-of-thumb consumers is large enough, a Taylor-type rule must imply a (permanent) change in the nominal interest rate in response to a (permanent) change in inflation that is significantly above unity, in order to guarantee the uniqueness of equilibrium. Hence, the Taylor principle becomes too weak a criterion for stability when the share of rule-of-thumb consumers is large.

We also find that, independently of their weight in the economy, the presence of rule-of-thumb consumers cannot in itself overturn the conventional result on the sufficiency of the Taylor principle. Instead, we argue that it is the interaction of those consumers with countercyclical markups (resulting from sticky prices in our model)

\footnotetext{
${ }^{3}$ See, e.g., Taylor (1999b), and Clarida, Galí, and Gertler (2000). Orphanides (2001) argues that the Fed's failure to satisfy the Taylor principle was not intentional; instead it was a consequence of a persistent bias in their real-time measures of potential output.
} 
that lies behind our main result.

In addition to our analysis of a standard contemporaneous rule, we also investigate the properties of a forward-looking interest rate rule. We show that the conditions for a unique equilibrium under such a rule are somewhat different from those in a contemporaneous one. In particular, we show that when the share of rule-of-thumb consumers is sufficiently large it may not be possible to guarantee a (locally) unique equilibrium or, if it is possible, it may require that interest rates respond less than one-for-one to changes in expected inflation.

Our framework shares most of the features of recent dynamic optimizing sticky price models. ${ }^{4}$ The only difference lies in the presence of rule-of-thumb consumers, who are assumed to coexist with conventional Ricardian consumers. While the behavior that we assume for rule-of-thumb consumers is admittedly simplistic (and justified only on tractability grounds), we believe that their presence captures an important aspect of actual economies which is missing in conventional models. Empirical support of non-Ricardian behavior among a substantial fraction of households in the U.S. and other industrialized countries can be found in Campbell and Mankiw (1989). It is also consistent, at least prima facie, with the findings of a myriad of papers rejecting the permanent income hypothesis on the basis of aggregate data. While many authors have stressed the consequences of the presence of rule-of-thumb consumers for fiscal policy, ${ }^{5}$ the study of its implications for the design of monetary policy is largely non-existent. ${ }^{6}$

A number of papers in the literature have also pointed to some of the limitations

\footnotetext{
${ }^{4}$ See, e.g., Rotemberg and Woodford (1999), Clarida, Gali and Gertler (1999), or Woodford (2001).

${ }^{5}$ See, e.g., Mankiw (2000) and Galí, López-Salido and Vallés (2003c).

${ }^{6}$ A recent paper by Amato and Laubach (2003) constitutes an exception. In that paper the authors derive the appropriate loss function that a benevolent central banker should seek to minimize in the presence of habit formation and rule-of-thumb consumers.
} 
of the Taylor principle as a criterion for the stability properties of interest rate rules, in the presence of some departures from standard assumptions. Thus, Edge and Rudd (2002) and Roisland (2003) show how the Taylor criterion needs to be strengthened in the presence of taxes on nominal capital income. Fair (2003) argues that the Taylor principle is not a requirement for stability if aggregate demand responds to nominal interest rates (as opposed to real rates) and inflation has a negative effect on consumption expenditures (through its effects on real wages and wealth), as it is the case in estimated versions of his multicountry model. Christiano and Gust (1999) find that the stability properties of simple interest rate rules are significantly altered when the assumption of limited participation is introduced. Benhabib, Schmitt-Grohé and Uribe (2001a) demonstrate that an interest rate rule satisfying the Taylor principle will generally not prevent the existence of multiple equilibrium paths converging to the liquidity trap steady state that arises in the presence of a zero lower bound on nominal rates. The present paper can be viewed as complementing that work, by pointing to an additional independent source of deviations from the Taylor principle as a criterion for stability of monetary policy rules.

The rest of the paper is organized as follows. Section 2 lays out the basic model, and derives the optimality conditions for consumers and firms, as well as their loglinear counterparts. Section 3 contains an analysis of the equilibrium dynamics and its properties under our baseline interest rate rule, with a special emphasis on the conditions that the latter must satisfy in order to guarantee uniqueness. Section 4 examines the robustness of those results and the required modifications when a forward looking interest rate rules is assumed. Section 5 concludes. 


\section{A New Keynesian Model with Rule-of-Thumb Consumers}

The economy consists of two types households, a continuum of firms producing differentiated intermediate goods, a perfectly competitive final goods firm, and a central bank in charge of monetary policy. Next we describe the objectives and constraints of the different agents. Except for the presence of rule-of-thumb consumers, our framework corresponds to a conventional New Keynesian model with staggered price setting à la Calvo used in numerous recent applications. A feature of our model that is worth emphasizing is the presence of capital accumulation. That feature has often been ignored in the recent literature, on the grounds that its introduction does not alter significantly most of the conclusions. ${ }^{7}$ In our framework, however, the existence of a mechanism to smooth consumption over time is critical for the distinction between Ricardian and non-Ricardian consumers to be meaningful, thus justifying the need for introducing capital accumulation explicitly. ${ }^{8}$

\subsection{Households}

We assume a continuum of infinitely-lived households, indexed by $i \in[0,1]$. A fraction $1-\lambda$ of households have access to capital markets where they can trade a full set of contingent securities, and buy and sell physical capital (which they accumulate and rent out to firms). We use the term optimizing or Ricardian to refer to that subset of households. The remaining fraction $\lambda$ of households do not own any assets

\footnotetext{
${ }^{7}$ Among the papers that introduce capital accumulation explicitly in a new Keynesian framework we can mention King and Watson (1996), Yun (1996), Dotsey (1999), Kim (2000) and Dupor (2002).

${ }^{8}$ Notice that in the absence of capital accumulation both types of households would behave identically in equilibrium, thus implying that constraint on the behavior of rule-of-thumb consumers would not be binding.
} 
nor have any liabilities; they just consume their current labor income. We refer to them as rule-of-thumb (or non-Ricardian) consumers. Different interpretations for the latter include myopia, lack of access to capital markets, fear of saving, ignorance of intertemporal trading opportunities, etc. Campbell and Mankiw (1989) provide some evidence, based on estimates of a modified Euler equation, of the quantitative importance of such rule-of-thumb consumers in the U.S. and other industrialized economies.

\subsubsection{Optimizing Households}

Let $C_{t}^{o}$, and $L_{t}^{o}$ represent consumption and leisure for optimizing households (henceforth we use a " $o$ " superscript to refer to optimizing households' variables). Preferences are defined by the discount factor $\beta \in(0,1)$ and the period utility $U\left(C_{t}^{o}, L_{t}^{o}\right)$. Optimizing households seek to maximize $E_{0} \sum_{t=0}^{\infty} \beta^{t} U\left(C_{t}^{o}, L_{t}^{o}\right)$, where $L_{t}^{o}+N_{t}^{o}=1$, subject to the sequence of budget constraints,

$$
P_{t}\left(C_{t}^{o}+I_{t}^{o}\right)+R_{t}^{-1} B_{t+1}=W_{t} N_{t}^{o}+R_{t}^{k} K_{t}^{o}+B_{t}+D_{t}
$$

and the capital accumulation equation

$$
K_{t+1}^{o}=(1-\delta) K_{t}^{o}+\phi\left(\frac{I_{t}^{o}}{K_{t}^{o}}\right) K_{t}^{o}
$$

Hence, at the beginning of the period the consumer receives labor income $W_{t} N_{t}^{o}$ (where $W_{t}$ denotes the nominal wage), and income from renting his capital holdings $K_{t}^{o}$ to firms at the (nominal) rental cost $R_{t}^{k}$. $B_{t}$ is the quantity of nominally riskless one-period bonds carried over from period $t-1$, and paying one unit of the numéraire in period $t . R_{t}$ denotes the gross nominal return on bonds purchased in period t. $D_{t}$ are dividends from ownership of firms. $P_{t} C_{t}^{o}$ and $P_{t} I_{t}^{o}$ denote, respectively, nominal expenditures on consumption and capital goods. Capital adjustment costs are introduced through the term $\phi\left(\frac{I_{t}^{o}}{K_{t}^{o}}\right) K_{t}^{o}$, which determines the change in the 
capital stock (gross of depreciation) induced by investment spending $I_{t}^{o}$. We assume $\phi^{\prime}>0$, and $\phi^{\prime \prime} \leq 0$, with $\phi^{\prime}(\delta)=1$, and $\phi(\delta)=\delta$. In what follows we specialize the period utility to take the form $U(C, L) \equiv \frac{1}{1-\sigma}\left(C L^{\nu}\right)^{1-\sigma}$ where $\sigma \geq 0$ and $\nu>0$.

The first order conditions for the optimizing consumer's problem can be written as:

$$
\begin{gathered}
\frac{C_{t}^{o}}{L_{t}^{o}}=\frac{1}{\nu} \frac{W_{t}}{P_{t}} \\
1=R_{t} E_{t}\left\{\Lambda_{t, t+1}\right\} \\
P_{t} Q_{t}=E_{t}\left\{\Lambda_{t, t+1}\left[R_{t+1}^{k}+P_{t+1} Q_{t+1}\left((1-\delta)+\phi_{t+1}-\left(\frac{I_{t+1}^{o}}{K_{t+1}^{o}}\right) \phi_{t+1}^{\prime}\right)\right]\right\} \\
Q_{t}=\frac{1}{\phi^{\prime}\left(\frac{I_{t}^{o}}{K_{t}^{o}}\right)}
\end{gathered}
$$

where $\phi_{t+1}=\phi\left(\frac{I_{t+1}^{o}}{K_{t+1}^{o}}\right)$ and $\phi_{t+1}^{\prime}=\phi^{\prime}\left(\frac{I_{t+1}^{o}}{K_{t+1}^{o}}\right)$, respectively; $\Lambda_{t, t+k}$ is the stochastic discount factor for nominal payoffs given by:

$$
\Lambda_{t, t+k} \equiv \beta^{k}\left(\frac{C_{t+k}^{o}}{C_{t}^{o}}\right)^{-\sigma}\left(\frac{L_{t+k}^{o}}{L_{t}^{o}}\right)^{\nu(1-\sigma)}\left(\frac{P_{t}}{P_{t+k}}\right)
$$

and where $Q_{t}$ is the (real) shadow value of capital in place, i.e., Tobin's $Q$. Notice that, under our assumption on $\phi$, the elasticity of the investment-capital ratio with respect to $Q$ is given by $-\frac{1}{\phi^{\prime \prime}(\delta) \delta} \equiv \eta$.

\subsubsection{Rule-of-Thumb Households}

Rule-of-thumb households do not attempt (or are just unable) to smooth their consumption path in the face of fluctuations in labor income. Each period they solve the static problem, i.e. they maximize their period utility $U\left(C_{t}^{r}, L_{t}^{r}\right)$ subject to the constraint that all their labor income is consumed, that is:

$$
P_{t} C_{t}^{r}=W_{t} N_{t}^{r}
$$

and where an " $r$ " superscript is used to denote variables specific to rule-of-thumb households. 
The associated first order condition is given by:

$$
\frac{C_{t}^{r}}{L_{t}^{r}}=\frac{1}{\nu} \frac{W_{t}}{P_{t}}
$$

which combined with (8) yields

$$
N_{t}^{r}=\frac{1}{1+\nu} \equiv N^{r}
$$

hence implying a constant employment for rule-of-thumb households ${ }^{9}$, as well as a consumption level proportional to the real wage: ${ }^{10}$

$$
C_{t}^{r}=\frac{1}{1+\nu} \frac{W_{t}}{P_{t}}
$$

\subsubsection{Aggregation}

Aggregate consumption and leisure are a weighted average of the corresponding variables for each consumer type. Formally:

$$
\begin{gathered}
C_{t} \equiv \lambda C_{t}^{r}+(1-\lambda) C_{t}^{o} \\
N_{t} \equiv \lambda N_{t}^{r}+(1-\lambda) N_{t}^{o}
\end{gathered}
$$

Similarly, aggregate investment and capital stock are given $I_{t} \equiv(1-\lambda) I_{t}^{o}$, and $K_{t} \equiv(1-\lambda) K_{t}^{o}$. We can combine (12) and (13) with the optimality conditions (9), (10), and (11) to obtain,

$$
N_{t}=\frac{\lambda}{1+\nu}+(1-\lambda) N_{t}^{o}
$$

\footnotetext{
${ }^{9}$ Alternatively we could have assumed directly a constant labor supply for rule of thumb households.

${ }^{10}$ Notice that under our assumptions, real wages are the only source of fluctuations in rule of thumb households' disposable income. More realistically, as shown in Gali, Lopez-Salido and Valles (2003c), the introduction of labor market frictions can generate fluctuations in hours of rule of thumb consumers, thus implying a second margin of variation in disposable income. In that context, it may be possible to preserve our findings even in the presence of wage stickiness (nominal or real). This constitutes a natural extension of this paper and is part of our ongoing research.
} 


$$
C_{t}=\frac{1}{\nu}\left(\frac{W_{t}}{P_{t}}\right)\left(1-N_{t}\right)
$$

which will be used below.

\section{$2.2 \quad$ Firms}

We assume the existence of a continuum of monopolistically competitive firms producing differentiated intermediate goods. The latter are used as inputs by a (perfectly competitive) firm producing a single final good.

\subsubsection{Final Goods Firm}

The final good is produced by a representative, perfectly competitive firm with a constant returns technology: $Y_{t}=\left(\int_{0}^{1} X_{t}(j)^{\frac{\varepsilon-1}{\varepsilon}} d j\right)^{\frac{\varepsilon}{\varepsilon-1}}$, where $X_{t}(j)$ is the quantity of intermediate good $j$ used as an input. Profit maximization, taking as given the final goods price $P_{t}$ and the prices for the intermediate goods $P_{t}(j)$, for all $j \in[0,1]$, yields the set of demand schedules, $X_{t}(j)=\left(\frac{P_{t}(j)}{P_{t}}\right)^{-\varepsilon} Y_{t}$. Finally, the zero profit condition yields, $P_{t}=\left(\int_{0}^{1} P_{t}(j)^{1-\varepsilon} d j\right)^{\frac{1}{1-\varepsilon}}$.

\subsubsection{Intermediate Goods Firm}

The production function for a typical intermediate goods firm (say, the one producing $\operatorname{good} j$ ) is given by:

$$
Y_{t}(j)=K_{t}(j)^{\alpha} N_{t}(j)^{1-\alpha}
$$

where $K_{t}(j)$ and $N_{t}(j)$ represents the capital and labor services hired by firm $j .{ }^{11}$ Cost minimization, taking the wage and the rental cost of capital as given, implies the optimality condition $\frac{K_{t}(j)}{N_{t}(j)}=\left(\frac{\alpha}{1-\alpha}\right)\left(\frac{W_{t}}{R_{t}^{k}}\right)$. Hence, real marginal cost is common to all firms and given by: $M C_{t}=\frac{1}{\Phi}\left(\frac{R_{t}^{k}}{P_{t}}\right)^{\alpha}\left(\frac{W_{t}}{P_{t}}\right)^{1-\alpha}$, where $\Phi \equiv \alpha^{\alpha}(1-\alpha)^{1-\alpha}$.

\footnotetext{
${ }^{11}$ Without loss of generality we have normalized the level of total factor productivity to unity.
} 
Price Setting Intermediate firms are assumed to set nominal prices in a staggered fashion, according to the stochastic time dependent rule proposed by Calvo (1983). Each firm resets its price with probability $1-\theta$ each period, independently of the time elapsed since the last adjustment. Thus, each period a measure $1-\theta$ of producers reset their prices, while a fraction $\theta$ keep their prices unchanged

A firm resetting its price in period $t$ will seek to maximize

$$
\max _{\left\{P_{t}^{*}\right\}} E_{t} \sum_{k=0}^{\infty} \theta^{k} E_{t}\left\{\Lambda_{t, t+k} Y_{t+k}(j)\left(P_{t}^{*}-P_{t+k} M C_{t+k}\right)\right\}
$$

subject to the sequence of demand constraints, $Y_{t+k}(j)=X_{t+k}(j)=\left(\frac{P_{t}^{*}}{P_{t+k}}\right)^{-\varepsilon} Y_{t+k}$, where $P_{t}^{*}$ represents the price chosen by firms resetting prices at time $t$. The first order conditions for this problem is:

$$
\sum_{k=0}^{\infty} \theta^{k} E_{t}\left\{\Lambda_{t, t+k} Y_{t+k}(j)\left(P_{t}^{*}-\frac{\varepsilon}{\varepsilon-1} P_{t+k} M C_{t+k}\right)\right\}=0
$$

Finally, the equation describing the dynamics for the aggregate price level is given by $P_{t}=\left[\theta P_{t-1}^{1-\varepsilon}+(1-\theta)\left(P_{t}^{*}\right)^{1-\varepsilon}\right]^{\frac{1}{1-\varepsilon}}$.

\subsection{Monetary Policy}

The central bank is assumed to set the nominal interest rate $r_{t} \equiv R_{t}-1$ every period according to a simple linear interest rate rule:

$$
r_{t}=r+\phi_{\pi} \pi_{t}+\phi_{y} y_{t}
$$

where $\phi_{\pi} \geq 0, \phi_{y} \geq 0$ and $r$ is the steady state nominal interest rate. Notice that the rule above implicitly assumes a zero inflation target, which is consistent with the steady state around which we will log linearize the price setting equation (16). A rule analogous to (17) was originally proposed by John Taylor (Taylor (1993)) as a description for the evolution of short-term interest rates in the U.S. under Greenspan. 
It has since become known as the Taylor rule and has been used in numerous theoretical and empirical applications. ${ }^{12}$ In addition to (17), we also analyze the properties of a forward-looking interest rate rule, in which interest rates respond to expected inflation and output. We refer the reader to the discussion below for details.

\subsection{Market Clearing}

The clearing of factor and good markets requires that the following conditions are satisfied for all $t: N_{t}=\int_{0}^{1} N_{t}(j) d j, K_{t}=\int_{0}^{1} K_{t}(j) d j, Y_{t}(j)=X_{t}(j)$, for all $j \in[0,1]$ and

$$
Y_{t}=C_{t}+I_{t}
$$

\subsection{Linearized Equilibrium Conditions}

Next we derive the log-linear versions of the key optimality and market clearing conditions that will be used in our analysis of the model's equilibrium dynamics. For aggregate variables we generally use lower case letters to denote the logs of the corresponding original variables (or their log deviations from steady state), and ignore constant terms throughout. Some of these conditions hold exactly, while others represent first-order approximations around a zero inflation steady state.

\subsubsection{Households}

The log-linearized versions of the households' optimality conditions, expressed in terms of aggregate variables, are presented next. The reader can find details of the derivations in a companion working paper. ${ }^{13}$ Some of these optimality conditions turn

\footnotetext{
${ }^{12}$ This is illustrated in many of the papers contained in the Taylor (1999) volume, which analyze the properties of rules like (17) or variations thereof in the context a a variety of models.

${ }^{13}$ See Galí, López-Salido and Vallés (2003a).
} 
out to be independent of $\lambda$, the weight of rule-of-thumb consumers in the economy. Among the latter we have the aggregate labor supply schedule that can be derived taking logs on both sides of (3):

$$
c_{t}+\varphi n_{t}=w_{t}-p_{t}
$$

where $\varphi \equiv \frac{N}{1-N}$. The latter coefficient, which can be interpreted as the inverse of the Frisch aggregate labor supply elasticity, can be shown to be independent of $\lambda .^{14}$

The log-linearized equations describing the dynamics of Tobin's $Q$ (6)and its relationship with investment (5)are also independent of $\lambda$, and given respectively by

$$
q_{t}=\beta E_{t}\left\{q_{t+1}\right\}+[1-\beta(1-\delta)] E_{t}\left\{\left(r_{t+1}^{k}-p_{t+1}\right)\right\}-\left(r_{t}-E_{t}\left\{\pi_{t+1}\right\}\right)
$$

and

$$
i_{t}-k_{t}=\eta q_{t}
$$

The same invariance to $\lambda$ holds for the log-linearized capital accumulation equation:

$$
k_{t+1}=\delta i_{t}+(1-\delta) k_{t}
$$

The only aggregate equilibrium condition that is affected by the weight of rule-ofthumb consumers turns out to be the log-linearized aggregate Euler equation, which takes the form

$$
c_{t}=E_{t}\left\{c_{t+1}\right\}-\frac{1}{\sigma}\left(r_{t}-E_{t}\left\{\pi_{t+1}\right\}-\rho\right)-\Theta E_{t}\left\{\Delta n_{t+1}\right\}
$$

where $\Theta \equiv \frac{\varphi \lambda}{1-\lambda}+\frac{\left(1-\frac{1}{\sigma}\right) \nu \varphi}{(1-\lambda)}$.

Notice that the possibility of a non-separable utility $(\sigma \neq 1)$ justifies in itself the presence of the term involving expected employment growth in the aggregate Euler equation. Notice, however, that in the absence of rule-of-thumb consumers we have

\footnotetext{
${ }^{14}$ More specifically, $\varphi$ is given by: $\varphi \equiv \frac{N}{1-N}=\frac{1}{\nu} \frac{(\rho+\delta)(1-\alpha)}{\rho+\delta(1-\alpha)+\mu(\rho+\delta)}$.
} 
$\Theta=\left(1-\frac{1}{\sigma}\right) \nu \varphi<1$, since $\nu \varphi \in(0,1)$. In general, however, the size of $\Theta$ is a highly nonlinear function of $\lambda$, the weight of rule-of-thumb consumers. As discussed below, that effect can potentially alter the local stability properties of the dynamical system describing the equilibrium.

\subsubsection{Firms}

Log-linearization of (16) and the definition of aggregate price level, around the zero inflation steady state, yields the familiar equation describing the dynamics of inflation as a function of the deviations of the average (log) markup from its steady state level

$$
\pi_{t}=\beta E_{t}\left\{\pi_{t+1}\right\}-\tau \mu_{t}
$$

where $\tau=\frac{(1-\beta \theta)(1-\theta)}{\theta}$ and (ignoring constant terms)

$$
\mu_{t}=\left(y_{t}-n_{t}\right)-\left(w_{t}-p_{t}\right)=\left(y_{t}-k_{t}\right)-\left(r_{t}^{k}-p_{t}\right)
$$

Furthermore, it can be shown that the following aggregate production function holds, up to a first order approximation:

$$
y_{t}=\alpha k_{t}+(1-\alpha) n_{t}
$$

\subsubsection{Market clearing}

Log-linearization of the market clearing condition of the final good around the steady state yields:

$$
y_{t}=\gamma_{c} c_{t}+\left(1-\gamma_{c}\right) i_{t}
$$

where $\gamma_{c} \equiv \frac{C}{Y}=1-\frac{\delta \alpha\left(1-\frac{1}{\varepsilon}\right)}{(\rho+\delta)}$ is the aggregate consumption share in the steady state, which is independent of the weight of rule-of-thumb consumers. 


\section{Analysis of Equilibrium Dynamics}

We can now combine equilibrium conditions (19)-(27) to obtain a system of difference equations describing the log-linearized equilibrium dynamics of our model economy. After several straightforward though tedious substitutions, we can reduce that system to one involving four variables:

$$
\mathbf{A} E_{t}\left\{\mathbf{x}_{t+1}\right\}=\mathbf{B} \mathbf{x}_{t}
$$

where $\mathbf{x}_{t} \equiv\left(n_{t}, c_{t}, \pi_{t}, k_{t}\right)^{\prime}$. Notice that $n_{t}, c_{t}, \pi_{t}, k_{t}$ are expressed in terms of $\log$ deviations from their values in the zero inflation steady state. The elements of matrices $\mathbf{A}$ and $\mathbf{B}$ are all functions of the underlying structural parameters. ${ }^{15}$

Notice that $\mathbf{x}_{t}=0$ for all $t$, which corresponds to the perfect foresight zero inflation steady state, always constitutes a solution to the above system. This should not be surprising, given that for simplicity we have not introduced any fundamental shocks in our model. In the remainder of the paper we study the conditions under which the solution to (28) is unique and converges to the steady state, for any given initial capital stock. In doing so we restrict our analysis to solutions of (28) (i.e., equilibrium paths) which remain within a small neighborhood of the steady state. ${ }^{16}$ Before we turn to that task, we discuss briefly the calibration that we use as a baseline for that analysis.

\subsection{Baseline Calibration}

The model is calibrated to a quarterly frequency. Table 1 summarizes compactly the values assumed for the different parameters in the baseline calibration. The rate of depreciation $\delta$ is set to 0.025 (implying a 10 percent annual rate). The elasticity of

\footnotetext{
${ }^{15}$ See the appendix in Galí, López-Salido and Vallés (2003a).

${ }^{16}$ See, e.g., Benhabib, Schmitt-Grohé and Uribe (2001a) for a discussion of the caveats associated with that approach.
} 
output with respect to capital, $\alpha$, is assumed to be $\frac{1}{3}$, a value roughly consistent with the observed labor income share given any reasonable steady state markup. With regard to preference parameters, we set the discount factor $\beta$ equal to 0.99 (implying a steady state real annual return of 4 percent). The elasticity of substitution across intermediate goods, $\varepsilon$, is set to 6 , a value consistent with a steady state markup $\mu$ of 0.2. The previous parameters are kept at their baseline values throughout the present section.

Next we turn to the parameters for which some sensitivity analysis is conducted, by examining a range of values in addition to their baseline settings. We set the baseline value for parameter $\nu$ in a way consistent with a unit Frisch elasticity of labor supply (i.e., $\varphi=1$ ) in our baseline calibration. That choice is associated with a fraction of time allocated to work in the steady state given by $N=\frac{1}{2}$. We choose a baseline value of one for $\sigma$, which corresponds to a separable (log-log) utility specification. The fraction of firms that keep their prices unchanged, $\theta$, is given a baseline value of 0.75 , which corresponds to an average price duration of one year. This is consistent with the findings reported in Taylor (1999c). Following King and Watson (1996), we set $\eta$, the elasticity of investment with respect to Tobin's $Q$, equal to 1.0 under our baseline calibration. ${ }^{17}$ Finally, we set $\phi_{\pi}=1.5$ and $\phi_{y}=0.5$ as the baseline values for the interest rate rule coefficients, in a way consistent with Taylor's (1993) characterization of U.S. monetary policy under Greenspan.

Much of the sensitivity analysis below focuses on the weight of rule-of-thumb households $(\lambda)$ and its interaction with $\theta, \sigma, \varphi, \eta$, and $\phi_{\pi}$ and $\phi_{y}$.

\footnotetext{
${ }^{17}$ Other authors who have worked with an identical specification of capital adjustment costs have considered alternative calibrations of that elasticity. Thus, e.g., Dotsey (1999) assumes an elasticity of 0.25; Dupor (2002) assumes a baseline elasticity of 5; Baxter and Crucini (1993) set a baseline value of 15; Abel (1980) estimates that elasticity to be between 0.3 and 0.5 .
} 


\subsection{Determinacy Analysis}

Vector $\mathbf{x}_{t}$ contains three non-predetermined variables (hours, consumption and inflation) and a predetermined one (capital stock). Hence, the solution to (28) is unique if and only if three eigenvalues of matrix $A^{-1} B$ lie outside the unit circle, and one lies inside. ${ }^{18}$ Alternatively, if there is more than one eigenvalue of $A^{-1} B$ inside the unit circle the equilibrium is locally indeterminate: for any initial capital stock there exists a continuum of deterministic equilibrium paths converging to the steady state, and the possibility of stationary sunspot fluctuations arises. On the other hand, if all the eigenvalues $A^{-1} B$ lie outside the unit circle, there is no solution to (28) that converges to the steady state, unless the initial capital stock happens to be at its steady state level (in which case $\mathbf{x}_{t}=0$ for all $t$ is the only non-explosive solution). Below our focus is on how the the presence of rule-of-thumb consumers may influence the configuration of eigenvalues of the dynamical system, and hence the properties of the equilibrium.

\subsection{The Taylor Principle and Indeterminacy}

We start by exploring the conditions for the existence of a unique equilibrium as a function of the degree of price stickiness (indexed by parameter $\theta$ ) and the weight of rule-of-thumb households (indexed by parameter $\lambda$ ) under an interest rate rule like (17). As shown by Bullard and Mitra (2002) and Woodford (2001), in a version of the model above with neither capital nor rule-of-thumb consumers, a necessary and sufficient condition for the existence of a (locally) unique equilibrium is given by ${ }^{19}$

$$
\phi_{\pi}>1-\frac{(1-\beta) \phi_{y}}{\tau(1+\varphi)}
$$

A rule like (17) which meets the condition above is said to satisfy the Taylor

\footnotetext{
${ }^{18}$ See, e.g., Blanchard and Kahn (1980).

${ }^{19}$ As in Bullard and Mitra (2002) we restrict ourselves to non-negative values of $\phi_{\pi}$ and $\phi_{y}$.
} 
principle. As discussed in Woodford (2001), such a rule guarantees that in response to permanent change in inflation (and, hence, in output), the nominal interest rate is adjusted more than one-for-one. In the particular case of a zero coefficient on output the Taylor principle is satisfied whenever $\phi_{\pi}>1$. More generally, as (29) makes clear, it is possible for the equilibrium to be unique for values of $\phi_{\pi}$ less than one, as long as as the central bank raises the interest rate sufficiently in response to an increase in output. In other words, in the canonical model there is some substitutability between the size of the response to output and that of the response to inflation. As shown in Dupor (2002) and further illustrated below, the previous finding carries over, at least qualitatively, to a version of the model with capital accumulation and fully Ricardian consumers. In particular, when $\phi_{y}=0$ the condition for uniqueness is given by $\phi_{\pi}>1$

Next we analyze the extent to which those conditions need to be modified in order to guarantee the existence of a unique equilibrium in the model with rule-ofthumb consumers laid out above. A key finding of our paper is illustrated by Figure 1. That figure represents the equilibrium properties of our model economy for all configurations of $\lambda$ and $\theta$, under the assumption of $\phi_{\pi}=1.5$ and $\phi_{y}=0.5$, parameter values that clearly satisfy the Taylor criterion in standard models. In particular, the figure displays the regions in the parameter space $(\lambda, \theta)$ that are associated with the presence of uniqueness and multiplicity of a rational expectations equilibrium in a neighborhood of the steady state. Notice that each graph corresponds to an alternative pair of settings for the risk aversion coefficient $\sigma$ and the inverse labor supply elasticity $\varphi$.

A key finding emerges clearly: the combination of a high degree of price stickiness with a large share of rule-of-thumb consumers rules out the existence of a unique equilibrium converging to the steady state. Instead, the economy is characterized 
in that case by indeterminacy of equilibrium (dark region). Conversely, if (a) prices are sufficiently flexible (low $\theta$ ) and/or (b) the share of rule-of-thumb consumers is sufficiently small (low $\lambda$ ), the existence of a unique equilibrium is guaranteed. That finding holds irrespective of the assumed values for $\sigma$ and $\varphi$, even though the relative size of the different regions can be seen to depend on those parameters. In particular, the size of the uniqueness region appears to shrink as $\sigma$ and $\varphi$ increase. In sum, as made clear by Figure 1, the Taylor principle may no longer be a useful criterion for the design of interest rate rules in economies with strong nominal rigidities and a substantial weight of rule-of-thumb consumers.

Importantly, while the previous result has been illustrated under the assumption of $\phi_{\pi}=1.5$ and $\phi_{y}=0.5$ (the values proposed by Taylor (1993)), similar patterns arise for a large set of configurations of those coefficients that would be associated with the existence of a unique equilibrium in the absence of rule-of-thumb consumers. The size of the indeterminacy region can be shown to shrink gradually as the size of the interest rate response to inflation and output increases (while keeping other parameters constant). In particular, for any given value of the output coefficient, $\phi_{y}$ (and given a configuration of settings for the remaining parameters), the minimum threshold value for the inflation coefficient $\phi_{\pi}$ consistent with an unique equilibrium lies above the one corresponding to the model without rule-of-thumb consumers. In other words, a strengthened condition on the size of the response of interest rates to changes in inflation is required in that case. Next, we provide an explicit analysis of the variation in the threshold value for $\phi_{\pi}$, as a function of different parameter values and, most importantly, as a function of the share of rule-of-thumb households. 


\subsection{Interest Rate Rules and Rule-of-Thumb Consumers: Re- quirements for Stability}

Figure 2 plots the threshold value of $\phi_{\pi}$ that is required for a unique equilibrium as a function of the share of rule-of-thumb consumers, for three alternative values of $\phi_{y}$ : 0.5 (our baseline case), 0.0 (the pure inflation targeting case) and 1.0 (as in the modified Taylor rule considered in Taylor (1999c)). For convenience, we plot the inverse of the threshold value of $\phi_{\pi} \cdot{ }^{20}$ We notice that as $\phi_{y}$ increases, the threshold value for $\phi_{\pi}$ falls, for any given share of rule-of-thumb consumers. Yet, as the Figure makes clear, the fact that the central bank is responding to output does not relieve it from the need to respond to inflation on a more than one-for-one basis, once a certain share of rule-of-thumb consumers is attained. Furthermore, as in our baseline case, the size of the minimum required response is increasing in that share. Thus, for instance, when $\phi_{y}=0.0$ the central bank needs to vary the nominal rate in response to changes in inflation on a more than one-for-one basis whenever the share of rule-ofthumb consumers is above 0.57 . In particular, when $\lambda=\frac{2}{3}$, the inflation coefficient $\phi_{\pi}$ must lie above 6 (approximately) in order to guarantee a unique equilibrium. Even though our simple-minded rule-of-thumb consumers do not have a literal counterpart that would allow us to determine $\lambda$ with precision, we view these values as falling within the range of empirical plausibility given some of the existing micro and macro evidence. In particular, estimated Euler equations for aggregate consumption whose specification allows for the presence of rule-of-thumb consumers point to values for $\lambda$ in the neighborhood of one-half (Campbell and Mankiw (1989)). In addition, and as recently surveyed in Mankiw (2000), recent empirical microeconomic evidence tends to support that finding. ${ }^{21}$

\footnotetext{
${ }^{20}$ The inverse of the threshold value is bounded, which facilitates graphical display.

${ }^{21}$ Empirical estimates of the marginal propensity to consume out of current income range from 0.35 up to 0.6 (see Souleles (1999)) or even 0.8 (see Shea (1995)), values that are well above those
} 
Figures 3a - 3d, display similar information for alternative calibrations of $\theta, \varphi$, $\eta$, and $\sigma$, respectively, with all other parameters set at their baseline values in each case. For convenience we set $\phi_{y}=0$, for in that case the Taylor principle takes a very simple form: the threshold value for $\phi_{\pi}$ in the absence of rule-of-thumb consumers is equal to one, which provides a convenient benchmark. The picture that emerges is, qualitatively, similar to that of Figure 2 with $\phi_{y}=0$. Notice first that, in every case considered, the threshold value for $\phi_{\pi}$ is equal to one, so long as the weight of rule-of-thumb consumers is sufficiently low. Once a certain weight for $\lambda$ is attained, the lower bound for $\phi_{\pi}$ can be seen to increase rapidly with the share of rule-ofthumb consumers. Regarding the influence of the parameters under consideration, the main qualitative findings can be summarized as follows: the deviation from the Taylor principle criterion seems to become more likely and/or quantitatively larger the stronger is the degree of price stickiness (i.e., the higher is $\theta$ ), the lower is the labor supply elasticity (i.e., the higher is $\varphi$ ), the more convex capital adjustment costs are (i.e., the lower is $\eta$ ), and the higher is the risk aversion parameter $\sigma$.

\subsection{Impulse Responses and Economic Mechanisms}

As discussed above, in the standard new Keynesian framework with a representative consumer, the Taylor principle generally constitutes the appropriate criterion for determining whether an interest rate rule of the sort considered in the literature will guarantee or not a unique equilibrium, and thus rule out the possibility of sunspotdriven fluctuations. The basic intuition goes as follows. Suppose that, in the absence of any shock to fundamentals that could justify it, there was an increase in the level of economic activity, with agents anticipating the latter to return only gradually to its implied by the permanent income hypothesis. On the other hand Wolff (1998) reports that the mean net worth of the lowest two quintiles of the US wealth distribution is only $\$ 900$. 
original (steady state) level. That increase in economic activity would be associated with increases in hours, lower markups (because of sticky prices), and persistently high inflation (resulting from the attempts by firms adjusting prices to re-establish their desired markups). But an interest rate rule that satisfied the Taylor principle would generate high real interest rates along the adjustment path, and hence, would call for a low level of consumption and investment relative to the steady state. The implied impact on aggregate demand would make it impossible to sustain the initial boom, thus rendering it inconsistent with a rational expectations equilibrium.

Consider instead the dynamic response of the economy to such an exogenous revision in expectations when the weight of rule-of-thumb consumers is sufficiently high to allow for multiple equilibria even though the interest rate rule satisfies the Taylor principle. That response is illustrated graphically in Figure 4, which displays the simulated responses to an expansionary sunspot shock for a calibrated version of our model economy meeting the above criteria. In particular we set $\phi_{\pi}=1.5$, $\phi_{y}=0.5$ and $\lambda=0.85$. The presence of rule-of-thumb consumers, combined with countercyclical markups, makes it possible to break the logic used above to rule out a sunspot-driven variation in economic activity. Two features are critical here. First, the decline in markups resulting from sluggish price adjustment allows real wages to go up (this effect is stronger in economies with a low labor supply elasticity) in spite of the decline in labor productivity associated with higher employment. Secondly, and most importantly, the increase in real wages generates a boom in consumption among rule-of-thumb consumers. If the weight of the latter in the economy is sufficiently important, the rise in their consumption will more than offset the decline in that of Ricardian consumers, as well as the drop in aggregate investment (both generated by the rise in interest rates). As a result, aggregate demand will rise, thus making it possible to sustain the persistent boom in output that was originally anticipated 
by agents. That possibility is facilitated by the presence of highly convex adjustment costs (low $\eta$ ), which will mute the investment response, together with a low elasticity of intertemporal substitution (a high $\sigma$ ), which will dampen the response of the consumption of Ricardian households.

\section{A Forward-Looking Rule}

In the present section we analyze the properties of our model when the central bank follows a forward-looking interest rate rule of the form

$$
r_{t}=r+\phi_{\pi} E_{t}\left\{\pi_{t+1}\right\}+\phi_{y} E_{t}\left\{y_{t+1}\right\}
$$

The rule above corresponds to a particular case of the specification originally proposed by Bernanke and Woodford (1997), and estimated by Clarida, Galí and Gertler $(1998,2000) .^{22}$ Dupor (2002) analyzes the equilibrium properties of a rule identical to (30) in the context of a new Keynesian model with capital accumulation similar to the one used in the present paper, though without rule-of-thumb consumers. His analysis suggests that the Taylor principle remains a useful criterion for this kind of economies, but with an important additional constraint: $\phi_{\pi}$ should not lie above some upper limit $\phi_{\pi}^{u}>1$ (which in turn depends on $\phi_{y}$ ) in order for the rational expectations equilibrium to be (locally) unique. In other words, in addition to the usual lower bound associated to the Taylor principle, there is an upper bound to the size of the response to expected inflation that must be satisfied; if that upper bound is overshot the equilibrium becomes indeterminate. A similar result has been shown analytically in the context of a similar model without capital. See, e.g., Bernanke

\footnotetext{
${ }^{22}$ In Galí, López-Salido and Vallés (2003a) we also provide an analysis of the properties of a backward looking rule. For the most part those properties are qualitatively similar to those of a forward looking rule.
} 
and Woodford (1997) and Bullard and Mitra (2002). ${ }^{23}$

How does the presence of rule-of-thumb consumers affect the previous result? Figure 5 represents graphically the interval of $\phi_{\pi}$ values for which a unique equilibrium exists, as a function of the weight of rule-of-thumb consumers $\lambda$, and for alternative values of $\phi_{y}$.

First, when $\phi_{y}=0$ and for low values of $\lambda$ (roughly below 0.6) the qualitative result found in the literature carries over to our economy: the uniqueness requires that $\phi_{\pi}$ lies within some interval bounded below by 1 . Interestingly, for this region, the size of that interval shrinks gradually as $\lambda$ increases. That result is consistent with the findings of Dupor (2002) for the particular case of $\lambda=0$ (no rule-of-thumb consumers).

Most interestingly (and surprisingly), when the weight of rule-of-thumb consumers $\lambda$ lies above a certain threshold, the properties of the forward-looking rule change dramatically. In particular, a value for $\phi_{\pi}$ below unity is needed in order to guarantee the existence of a unique rational expectations equilibrium. In other words, the central bank would be ill advised if it were to follow a forward-looking rule satisfying the Taylor principle, since that policy would necessarily generate an indeterminate equilibrium. $^{24}$

A systematic response of the interest rate to changes in output $\left(\phi_{y}>0\right)$, even if small in size, has a significant impact on the stability properties of our model economy. Thus, for low values of $\lambda$, a positive setting for $\phi_{y}$ tends to raise the upper threshold for $\phi_{\pi}$ consistent with a unique equilibrium. As seen in the four consecutive

\footnotetext{
${ }^{23}$ More recently, Levin, Wieland and Williams (2003) have shown that the existence of such an upper threshold is inherent to a variety of forward-looking rules, with the uniqueness region generally shrinking as the forecast horizon is raised.

${ }^{24}$ See Galí, López-Salido and Vallés (2003a) for a discussion of the reasons why a large presence of rule-of-thumb consumers make it possible for a rule that responds less than one-for-one to (expected) inflation to be consistent with a unique equilibrium.
} 
graphs of Figure 5, the effect of $\phi_{y}$ on the size of the uniqueness region appears to be non-monotonic, increasing very quickly for low values of $\phi_{y}$ and shrinking back gradually for higher values. On the other hand, for higher values of $\lambda$, the opposite effect takes place: the interval of $\phi_{\pi}$ values for which there is a unique equilibrium becomes smaller as we increase the size of the output coefficient relative to the $\phi_{y}=0$ case. In fact, under our baseline calibration, when $\phi_{y}=0.5$ and for $\lambda$ sufficiently high, an indeterminate equilibrium arises regardless of the value of the inflation coefficient.

The high sensitivity of the model's stability properties to the size of the output coefficient in a forward-looking interest rate rule in a model with capital accumulation (but no rule-of-thumb consumers) had already been noticed by Dupor (2002). The above analysis raises an important qualification (and warning) on such earlier results: in the presence of rule-of-thumb consumers an aggressive response to output does not seem warranted, for it can only reduce the region of inflation coefficients consistent with a unique equilibrium. On the other hand, a small response to output has the opposite effect: it tends to enlarge the size of the uniqueness region.

In summary, when the central bank follows a forward-looking rule like (30) the presence of rule-of-thumb consumers either shrinks the interval of $\phi_{\pi}$ values for which the equilibrium is unique (in the case of low $\lambda$ ), or makes a passive policy necessary to guarantee that uniqueness (for high values of $\lambda$ ).

\section{Concluding Remarks}

The Taylor principle, i.e., the notion that central banks should raise (lower) nominal interest rates more than one-for-one in response to a rise (decline) in inflation, is generally viewed as a prima facie criterion in the assessment of a monetary policy. Thus, an interest rate rule that satisfies the Taylor principle is viewed as a policy with stabilizing properties, whereas the failure to meet the Taylor criterion is often 
pointed to as a possible explanation for periods characterized by large fluctuations in inflation and widespread macroeconomic instability.

In the present paper we have provided a simple but potentially important qualification to that view. We have shown how the presence of rule-of-thumb (non-Ricardian) consumers in an otherwise standard dynamic sticky price model, can alter the properties of simple interest rate rules dramatically. The intuition behind the important role played by rule-of-thumb consumers is easy to grasp: the behavior of those households is, by definition, insulated from the otherwise stabilizing force associated with changes in real interest rates. We summarize our main results as follows.

1. Under a contemporaneous interest rate rule, the existence of a unique equilibrium is no longer guaranteed by the Taylor principle when the weight of ruleof-thumb consumers attains a certain threshold. Instead the central bank may be required to pursue a more anti-inflationary policy than it would otherwise be needed.

2. Under a forward-looking interest rate rule, the presence of rule-of-thumb consumers also complicates substantially the central bank's task, by shrinking the range of responses to inflation consistent with a unique equilibrium (when the share of rule-of-thumb consumers is relatively low), or by requiring that a passive interest rate rule is followed (when the share of rule-of-thumb consumers is large).

We interpret the previous results as raising a call for caution on the part of central banks when designing their monetary policy strategies: the latter should not ignore the potential importance of rule-of-thumb consumers (or, more broadly speaking, procyclical components of aggregate demand that are insensitive to interest rates). From that viewpoint, our findings suggest that if the share of rule-of-thumb consumers is 
non-negligible the strength of the interest rate response to contemporaneous inflation may have to be increased in order to avoid multiple equilibria. But if that share takes a high value, the size of the response required to guarantee a unique equilibrium may be too large to be credible, or even to be consistent with a non-negative nominal rate. In that case, our findings suggest that the central bank should consider adopting a passive rule that responds to expected inflation only (as an alternative to a rule that responds to current inflation with a very high coefficient). It is clear, however, that such an alternative would have practical difficulties, especially from the viewpoint of communication with the public.

The above discussion notwithstanding, it is not the objective of the present paper to come up with specific policy recommendations: our model is clearly too simplistic to be taken at face value, and any sharp conclusion coming out of it might not be robust to alternative specifications. On the other hand we believe our analysis is useful in at least one regard: it points to some important limitations of the Taylor principle as a simple criterion for the assessment of monetary policy when rule-ofthumb consumers (or the like) are present in the economy. In that respect, our findings call for caution when interpreting estimates of interest rate rules similar to the ones analyzed in the present paper in order to assess the merits of monetary policy in specific historical periods. ${ }^{25}$ In particular, our results suggest that evidence on the size of the response of interest rates to changes in inflation should not automatically be viewed as allowing for indeterminacy and sunspot fluctuations (if the estimates suggest that the Taylor principle is not met) nor, alternatively, as guaranteeing a unique equilibrium (if the Taylor principle is shown to be satisfied in the data). Knowledge of the exact specification of the interest rate rule (e.g. whether it is forward looking or not) as well as other aspects of the model would be required for

\footnotetext{
${ }^{25}$ See, e.g., Taylor (1999b) and Clarida, Galí, and Gertler (2000).
} 
a proper assessment of the stabilizing properties of historical monetary policy rules. In addition to its implications for the stability of interest rate rules, the presence of rule-of-thumb consumers is also likely to have an influence in the nature of the central bank objective function. Early results along these lines, though in the context of a model somewhat different from the one in the present paper, can be found in Amato and Laubach (2003). We think that the derivation of optimal monetary policy rules as well as the assessment of simple policy rules using a welfare based criteria can be a fruitful line of research.

More generally, we believe that the introduction of rule-of-thumb consumers in dynamic general equilibrium models used for policy analysis not only enhances significantly the realism of those models, but it can also allow us to uncover interesting insights that may be relevant for the design of policies and helpful in our efforts to understand many macroeconomic phenomena. An illustration of that potential usefulness can be found in a companion paper (Galí, López-Salido and Valles (2003c)), where we have argued that the presence of rule-of-thumb consumers may help account for the observed effects of fiscal policy shocks, some of which are otherwise hard to explain with conventional new Keynesian or neoclassical models. 


\section{References}

Abel, A. (1980): "Empirical Investment Equations. An integrated Framework," Carnegie Rochester Conference Series on Public Policy , 12, 39-91.

Amato, Jeffery, and Thomas Laubach (2003): "Rule-of-Thumb Behavior and Monetary Policy," European Economic Review, Vol 47 (5), 791-831.

Baxter, M. and M. Crucini, (1993): "Explaining Saving Investment Correlations," American Economic Review, vol. 83, no. 1, 416-436.

Benhabib, Jess, Stephanie Schmitt-Grohe, and Martin Uribe (2001a): "The Perils of Taylor Rules," Journal of Economic Theory 96, 40-69.

Benhabib, Jess, Stephanie Schmitt-Grohe, and Martin Uribe (2001b): "Monetary Policy and Multiple Equilibria," American Economic Review vol. 91, no. 1, 167-186.

Bernanke, Ben S., and Michael Woodford (1997): "Inflation Forecasts and Monetary Policy," Journal of Money, Credit and Banking, vol. 24, 653-684:

Blanchard, Olivier and Charles Kahn (1980), "The Solution of Linear Difference Models under Rational Expectations", Econometrica, 48, 1305-1311.

Bullard, James, and Kaushik Mitra (2002): "Learning About Monetary Policy Rules," Journal of Monetary Economics, vol. 49, no. 6, 1105-1130.

Campbell, John Y. and N. Gregory Mankiw (1989): "Consumption, Income, and Interest Rates: Reinterpreting the Time Series Evidence," in O.J. Blanchard and S. Fischer (eds.), NBER Macroeconomics Annual 1989, 185-216, MIT Press

Calvo, Guillermo, 1983, "Staggered Prices in a Utility Maximizing Framework," Journal of Monetary Economics, 12, 383-398.

Christiano, Lawrence J., and Christopher J. Gust (1999): "A Comment on Robustness of Simple Monetary Policy Rules under Model Uncertainty," in J.B. Taylor ed., Monetary Policy Rules, University of Chicago Press.

Clarida, Richard, Jordi Galí, and Mark Gertler (1998): “Monetary Policy Rules 
in Practice: Some International Evidence", European Economic Review, 42 (6), June 1998, pp. 1033-1067.

Clarida, Richard, Jordi Galí, and Mark Gertler (1999): "The Science of Monetary Policy: A New Keynesian Perspective," Journal of Economic Literature, vol. 37, 1661-1707.

Clarida, Richard, Jordi Galí, and Mark Gertler (2000): "Monetary Policy Rules and Macroeconomic Stability: Evidence and Some Theory," Quarterly Journal of Economics, vol. 105, issue 1, 147-180.

Dotsey, Michael (1999): "Structure from Shocks," Federal Reserve Bank of Richmond Working Paper 99-6.

Dupor, Bill (2002): "Interest Rate Policy and Investment with Adjustment Costs," manuscript.

Edge, Rochelle M., and Jeremy B. Rudd (2002): "Taxation and the Taylor Principle" Federal Reserve Board, finance and Economics Discussion Series no. 2002-51

Fair, Ray C. (2003): "Estimates of the Effectiveness of Monetary Policy," Journal of Money, Credit and Banking, forthcoming.

Galí, Jordi, J. David López-Salido, and Javier Vallés (2003a): "rule-of-thumb Consumers and the Design of Interest Rate Rules," Working Paper \# 0320, Banco de España.

Galí, Jordi, J. David López-Salido, and Javier Vallés (2003b): “Technology Shocks and Monetary Policy: Assessing the Fed's Performance," Journal of Monetary Economics, vol. 50, no. 4 .

Galí, Jordi, J. David López-Salido, and Javier Vallés (2003c): "Understanding the Effects of Government Spending on Consumption," mimeo Banco de España .

Kerr, William, and Robert G. King: "Limits on interest rate rules in the IS model," Economic Quarterly, Spring issue, 47-75. 
Kim, J. (2000), "Constructing and estimating a realistic optimizing model of monetary policy," Journal of Monetary Economics, vol. 45, Issue 2 , April 2000, 329-359

King, Robert, and Mark Watson (1996), "Money, Prices, Interest Rates and the Business Cycle" Review of Economics and Statistics, 78, 35-53

Levin, Andrew, Volker Wieland, John C. Williams (2002): "The Performance of Forecast-Based Monetary Policy Rules under Model Uncertainty," American Economic Review, vol. 93, no. 3, 622-645.

Mankiw, N. Gregory (2000): "The Savers-Spenders Theory of Fiscal Policy," American Economic Review, vol. 90, no. 2, 120-125.

McCallum, B. (1999): "Issues in the Design of Monetary Policy Rules", in J.B. Taylor and M. Woodford eds., Handbook of Macroeconomics, vol. 1c, 1341-1397, Elsevier, New York.

Orphanides, A. (2001), "Monetary Policy Rules based on Real Time Data," American Economic Review, vol. 91, no. 4, 964-985

Roisland, Oistein (2003): "Capital Income Taxation, Equilibrium Determinacy, and the Taylor Principle" Economics Letters 81, 147-153.

Rotemberg, J. and M. Woodford (1999): "Interest Rate Rules in an Estimated Sticky Price Model," in J.B. Taylor ed., Monetary Policy Rules, University of Chicago Press, 57-119.

Shea, John, (1995): "Union Contracts and the Life-Cycle/Permanent-Income Hypothesis, " American Economic Review vol. 85, 186-200.

Souleles, Nicholas S. (1999): "The Response of Household Consumption to Income Tax Refund," American Economic Review vol. 89, 947-958.

Taylor, John B. (1993): "Discretion versus Policy Rules in Practice," Carnegie Rochester Conference Series on Public Policy , December 1993, 39, 195-214. 
Taylor, John B. (1999a): Monetary Policy Rules, University of Chicago Press and NBER.

Taylor, John B. (1999b): "An Historical Analysis of Monetary Policy Rules," in J.B. Taylor ed., Monetary Policy Rules, University of Chicago Press.

Taylor, John B. (1999c): "Staggered Price and Wage Setting in Macroeconomics," in J.B. Taylor and M. Woodford eds., Handbook of Macroeconomics, chapter 15, 13411397, Elsevier, New York.

Woodford, Michael (2001): "The Taylor Rule and Optimal Monetary Policy," American Economic Review vol. 91, no. 2, 232-237.

Yun, Tack (1996): "Nominal Price Rigidity, Money Supply Endogeneity, and Business Cycles," Journal of Monetary Economics 37, 345-370.

Wolff, Edward (1998): "Recent trends in the size distribution of Household wealth", Journal of Economic Perspectives, 12(3), 131-150 
Table 1. Baseline Calibration

\begin{tabular}{|c|c|c|}
\hline Parameters & Values & Description of the Parameters \\
\hline$\delta$ & 0.025 & Depreciation rate \\
\hline$\alpha$ & $1 / 3$ & Elasticity of output with respect to capital \\
\hline$\beta$ & 0.99 & Discount factor \\
\hline$\varepsilon$ & 6 & Elasticity of substitution among intermediate goods \\
\hline$\varphi$ & 1 & Inverse of the (Frisch) labor supply elasticity \\
\hline$\sigma$ & 1 & Relative risk aversion \\
\hline$\theta$ & $3 / 4$ & Fraction of firms that leave their prices unchanged \\
\hline$\eta$ & 1 & Elasticity of investment to Tobin's Q \\
\hline$\phi_{\pi}$ & 1.5 & Inflation coefficient in interest rate rule \\
\hline$\phi_{y}$ & 0.5 & Output coefficient in interest rate rule \\
\hline
\end{tabular}




\section{Figure 1 \\ Rule-of-Thumb Consumers, Price Stickiness and Indeterminacy}
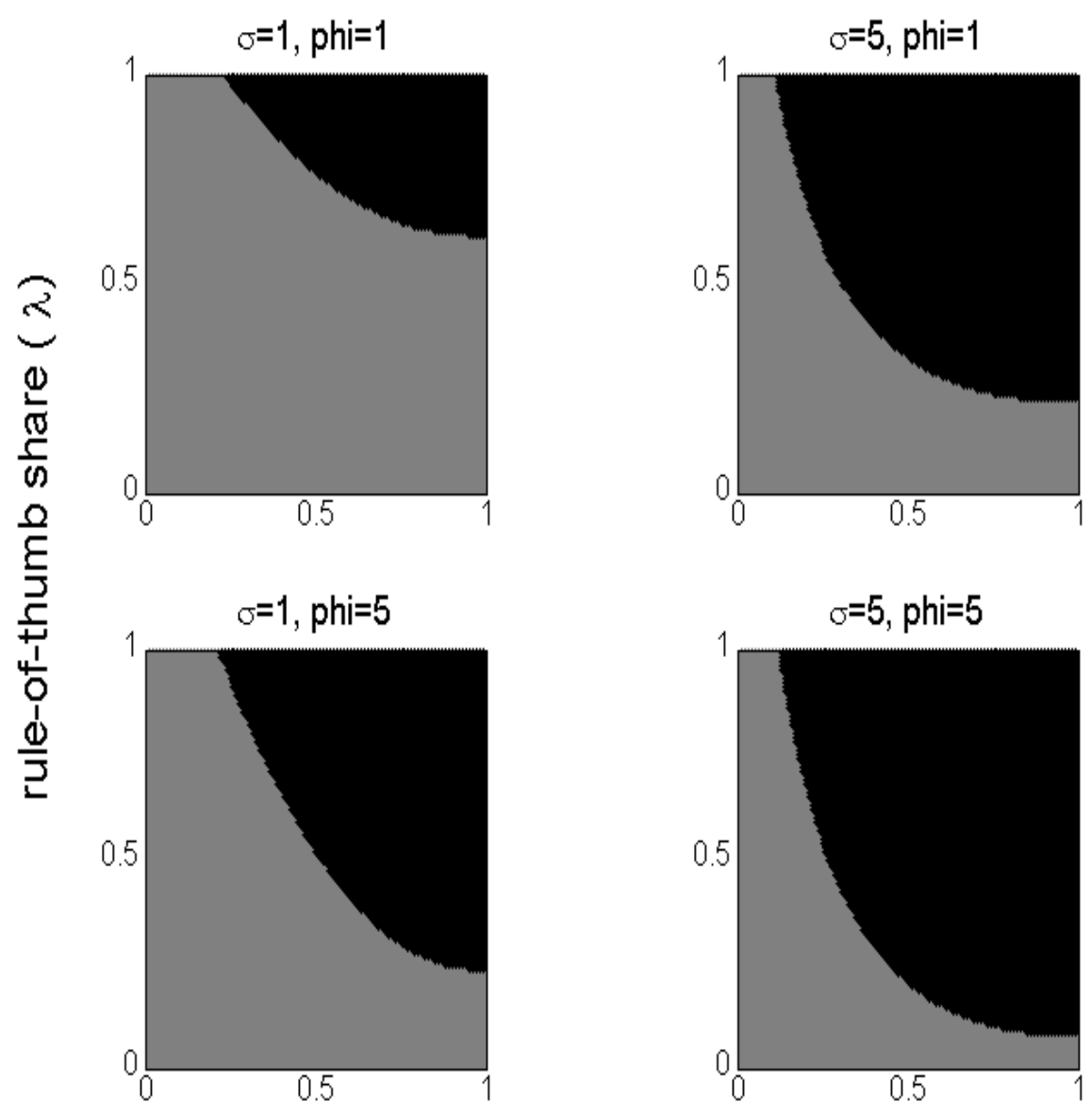

stickiness $(\theta)$

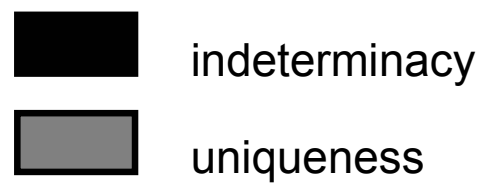

Note: Simulations based on the parameter values of the Table 1 and the baseline Taylor rule with $\Phi_{\mathrm{n}}=1.5$ and $\Phi_{\mathrm{y}}=0.5$. 
Figure 2

Rule-of-Thumb Consumers and the Threshold Inflation Coefficient

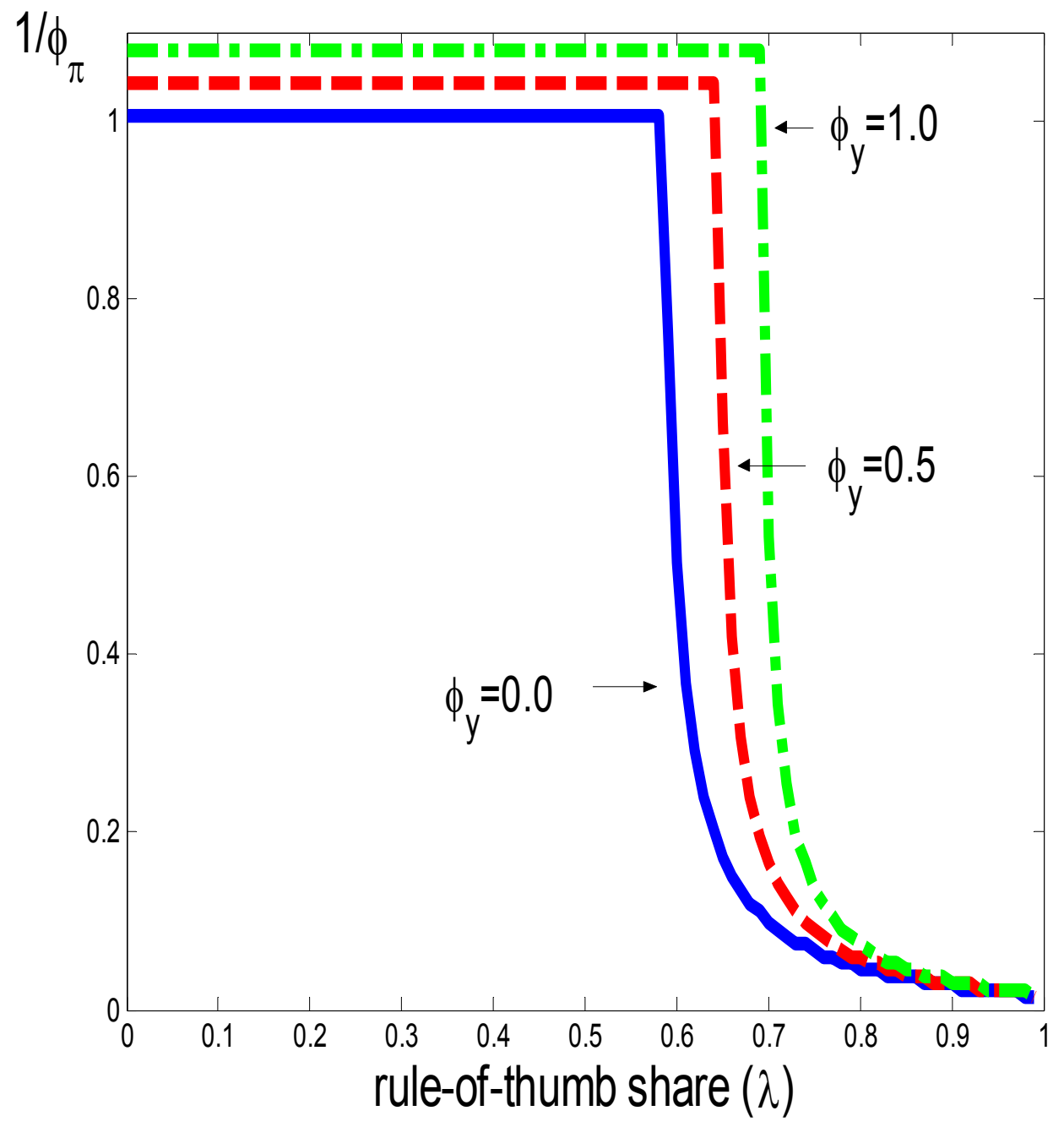

Note: Simulations based on the parameter values of the Table 1 and the baseline Taylor rule. The threshold inflation coefficient is the lowest value of $\Phi_{\Pi}$ that gurantees a unique solution. 
Figure 3

Rule-of-Thumb Consumers and the Threshold Inflation Coefficient

a. The Role of Price stickiness

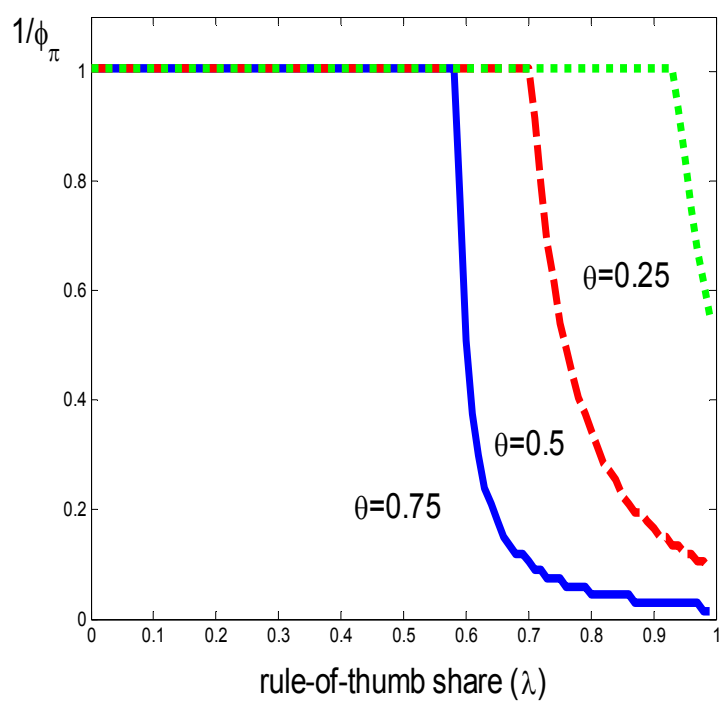

c. The Role of Capital Adjustment Costs

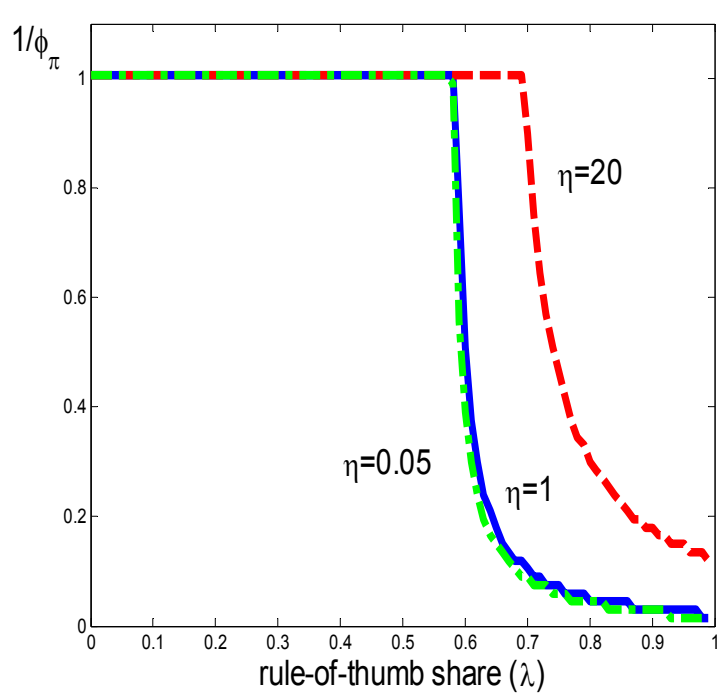

b. The Role of Labor Supply Elasticity

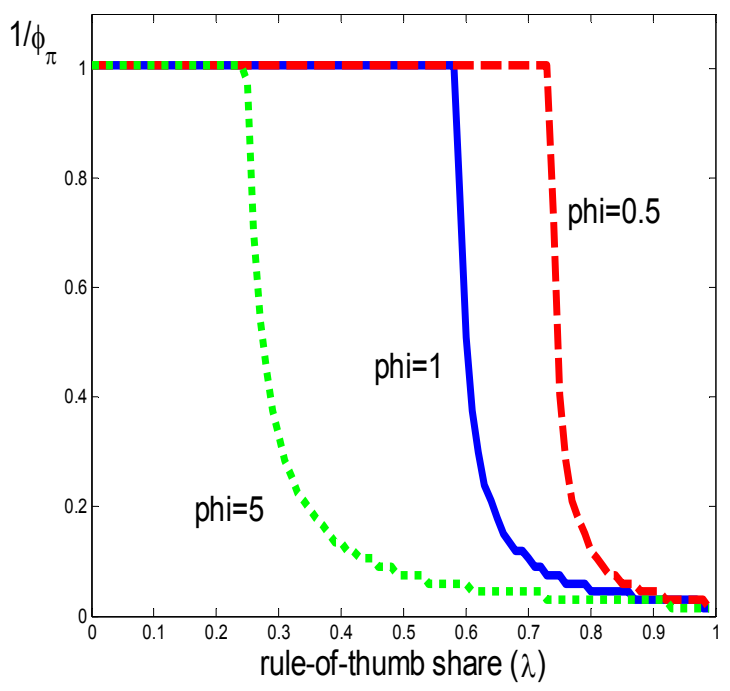

d. The Role of Risk Aversion

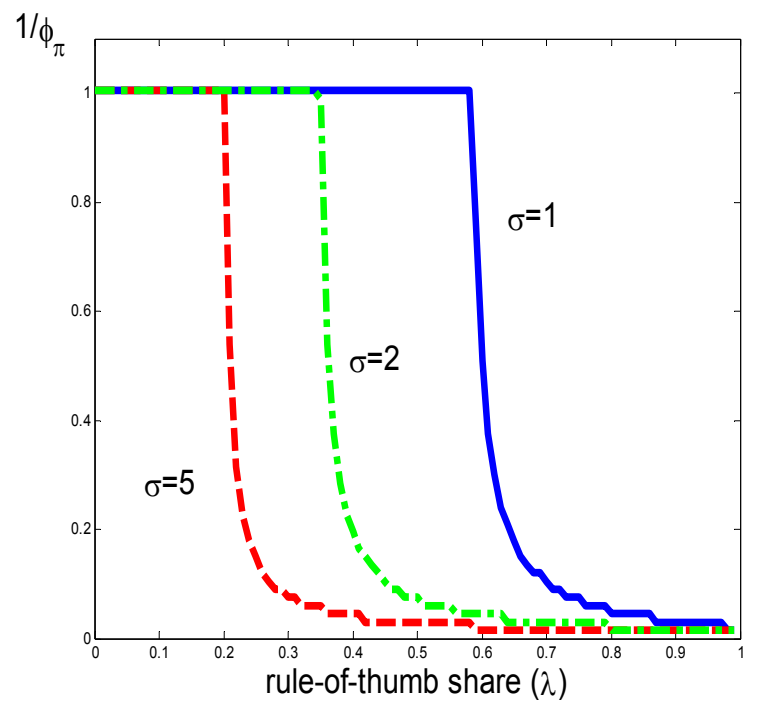

Note: Simulations based on the parameter values of the Table 1 and the baseline Taylor rule under $\Phi_{Y}=0$. The threshold inflation coefficient is the lowest value of $\Phi_{\Pi}$ that guarantees a unique solution. 
Figure 4

Dynamic Responses to a Sunspot Shock Baseline Taylor Rule $\left(\Phi_{\pi}=1.5, \Phi_{y}=0.5, \lambda=0.85\right)$
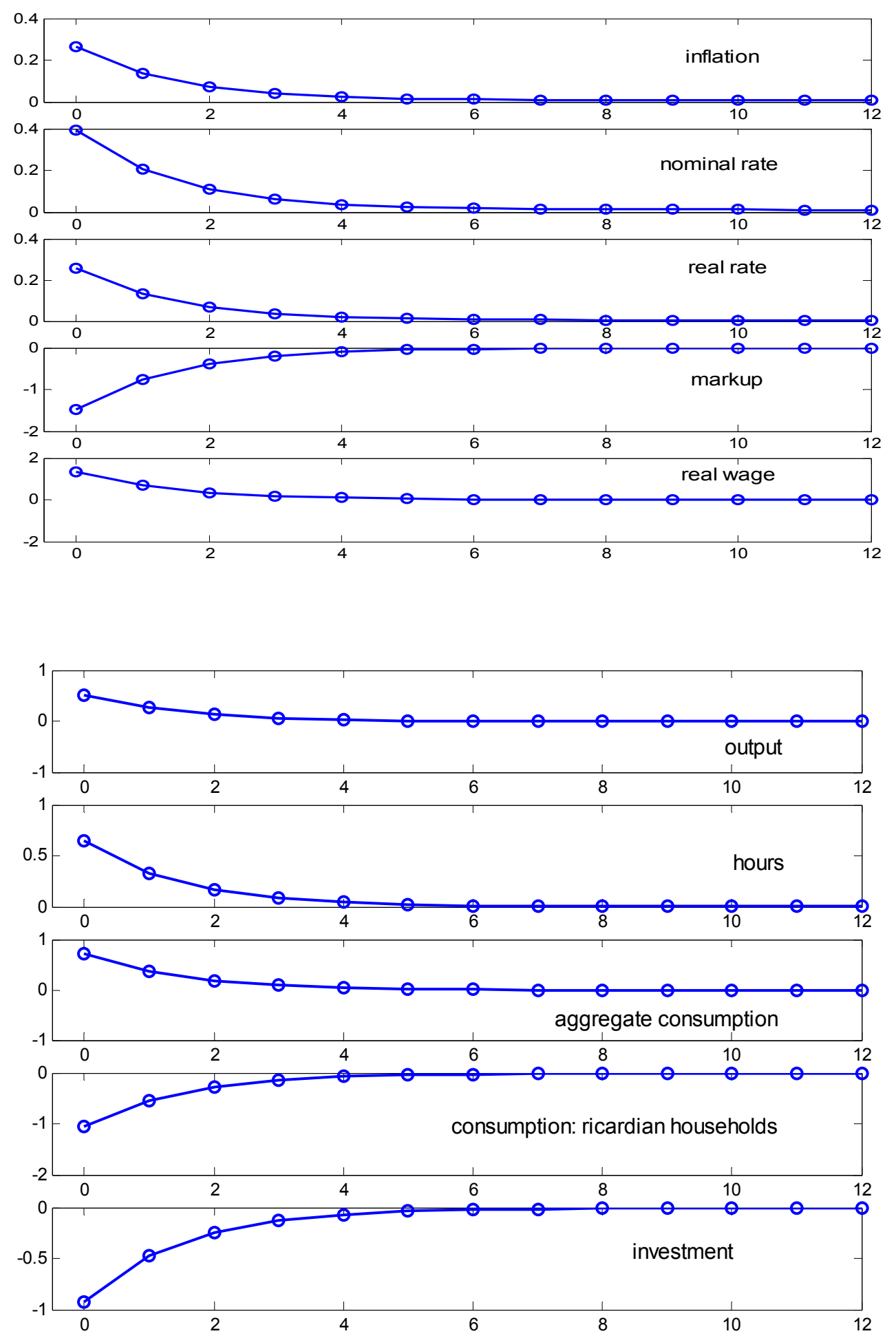

Note: Simulations based on the parameter values of the Table 1 and the baseline Taylor rule under $\Phi_{\pi}=1.5, \Phi_{y}=0.5, \lambda=0.85$. 


\section{Figure 5}

\section{Rule-of-Thumb Consumers and Indeterminacy \\ The Forward Looking Rule Taylor Rule}
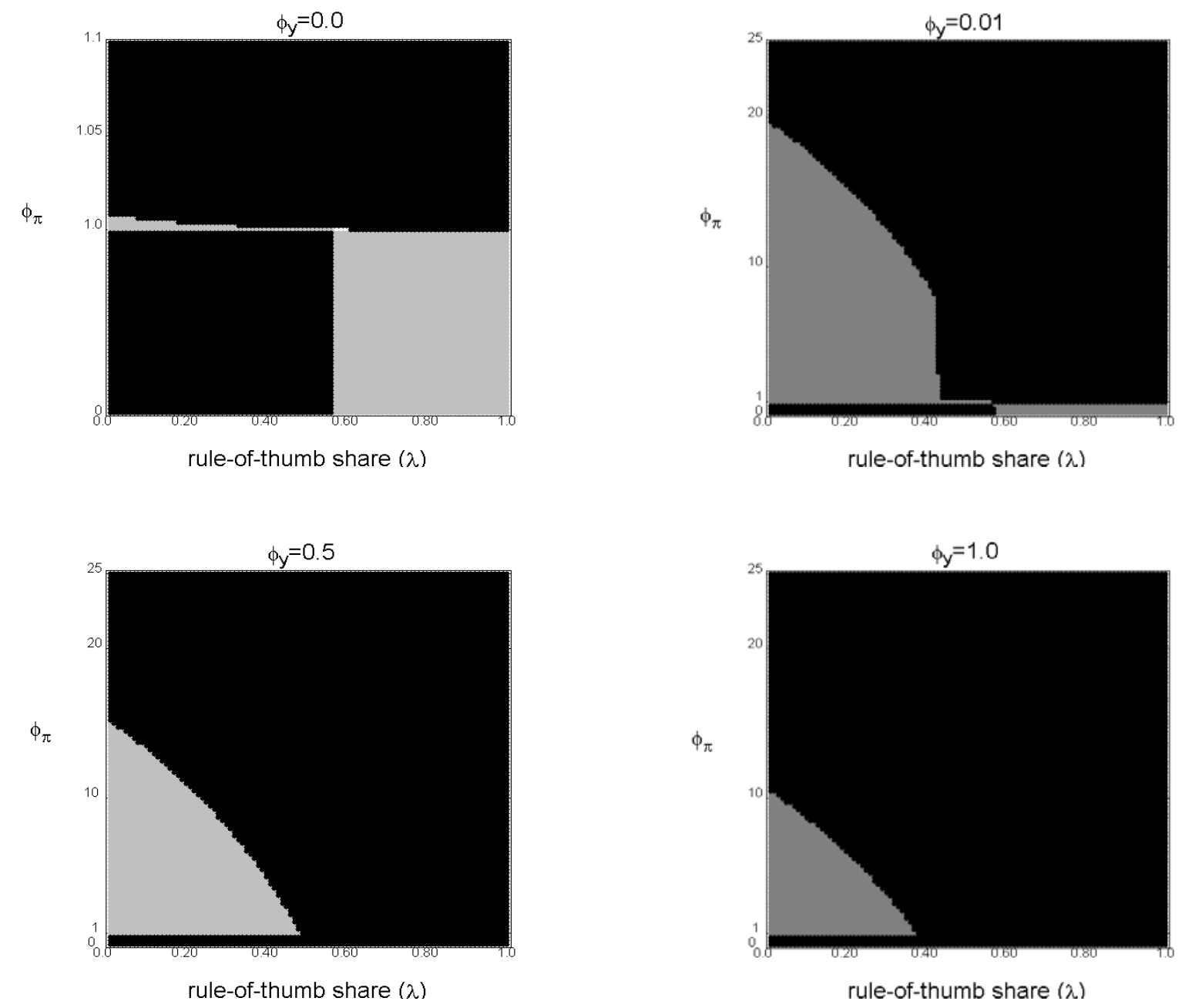

indeterminacy

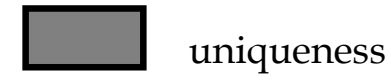

Note: Simulations based on the parameter values of the Table 1 and the forward looking Taylor rule. 
Figure 6

\section{Dynamic Responses to a Cost Push Shock when the Taylor Principle is not Met Forward Looking Rule}
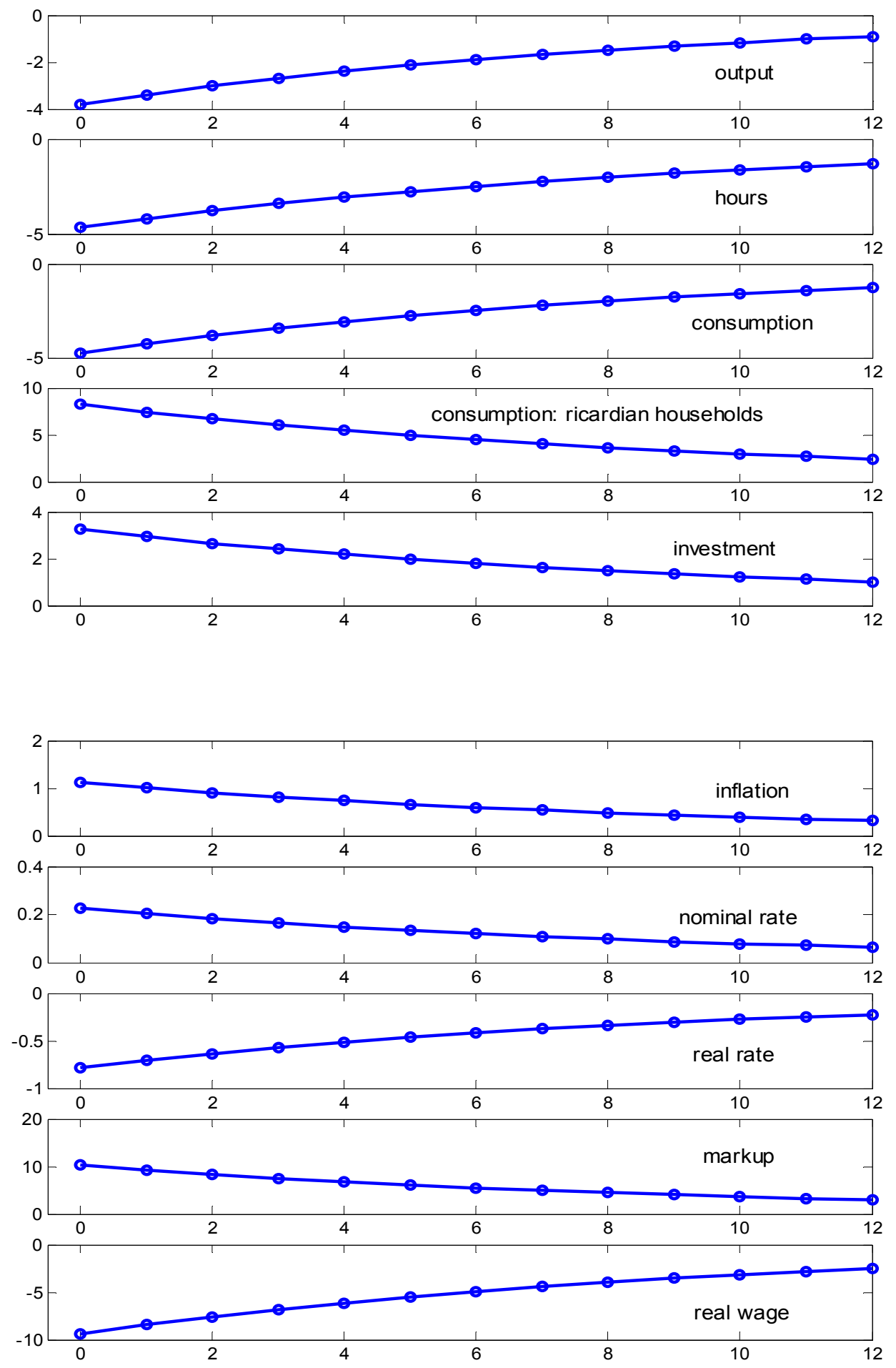

horizon

Note: Simulations based on parameter values of Table 1 , under $\lambda=0.85$ and a forward looking Taylor rule with $\Phi_{\mathrm{y}}=0$ and $\Phi_{\Pi}=0.2$ 